Tohoku J. Exp. Med., 2009, 219, 71-78

\title{
Intake of Repeatedly Heated Palm Oil Causes Elevation in Blood Pressure with Impaired Vasorelaxation in Rats
}

\author{
Xin-Fang Leong, ${ }^{1}$ Mohd Nadzri Mohd Najib, ${ }^{1}$ Srijit Das, ${ }^{2}$ Mohd Rais Mustafa ${ }^{3}$ and \\ Kamsiah Jaarin ${ }^{1}$

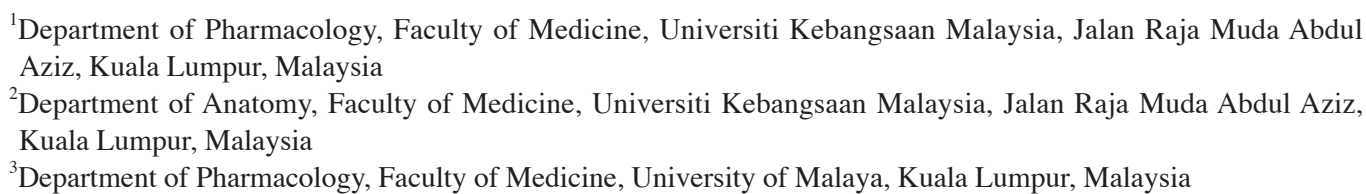

Oxidization of dietary cooking oil increases the risk of cardiovascular diseases such as hypertension by increasing the formation oxidative oxygen radicals. The aim of study was to investigate the effects of repeatedly heated palm oil on blood pressure, plasma nitrites, and vascular reactivity. Nitrites were measured, as an indirect marker for nitric oxide production. Male Sprague-Dawley rats were divided into four groups: control group fed with basal diet and other three groups fortified with 15\% weight/weight fresh palm oil (FPO), palm oil heated five times (5HPO) or palm oil heated ten times (10HPO) for 24 weeks. The oil was heated to $180^{\circ} \mathrm{C}$ for $10 \mathrm{~min}$. Blood pressure was measured at baseline and at intervals of four weeks for 24 weeks using non-invasive tail-cuff method. Following 24 weeks, the rats were sacrificed and thoracic aortas were dissected for measurement of vascular reactivity. Blood pressure was elevated significantly $(p<0.05)$ in 5HPO and 10HPO groups, with the 10HPO group showing higher values. Aortic rings from animals fed with heated oil showed diminished relaxation in response to acetylcholine or sodium nitroprusside, and greater contraction to phenylephrine. Acetylcholine and sodium nitroprusside cause endothelium-dependent and endothelium-independent relaxation, respectively. Relaxation responses remained unaltered in the FPO group, with the attenuated contractile response to phenylephrine, compared to control group. FPO increased plasma nitrites by $28 \%$, whereas $5 \mathrm{HPO}$ and $10 \mathrm{HPO}$ reduced them by $25 \%$ and $33 \%$, respectively. Intake of repeatedly heated palm oil causes an increase in blood pressure, which may be accounted for by the attenuated endothelium-dependent vasorelaxant response. Heating; palm oil; blood pressure; nitric oxide; aorta.

Tohoku J. Exp. Med., 2009, 219 (1), 71-78. (C) 2009 Tohoku University Medical Press

Past research confined to epidemiological observations, intervention trials and studies on experimental animals and humans have provided vital information on the evidence of the dietary fats on blood pressure (BP) (Ferrara et al. 2000; Psaltopoulou et al. 2004; Medeiros et al. 2005). Hypertension is one of the major risk factors involved in adverse cardiovascular outcomes such as coronary heart disease, atherosclerosis and stroke. The pathogenesis of hypertension is attributed to oxidative stress and endothelial dysfunction.

Diet-induced hypertension is associated with oxidative stress, which may reduce nitric oxide (NO) production or increase NO inactivation (Roberts et al. 2000). It was suggested that reduced NO production may be due to down regulation of vascular NO synthase (Roberts et al. 2005). Reactive oxygen species (ROS) such as superoxide anions have impact on the production and activity of endogenous vascular NO (Rubanyi 1988).

The endothelium maintains vascular homeostasis through release of regulatory substances including endothelium-derived relaxing factor which is best characterized as NO (Furchgott and Vanhoutte 1989). Endotheliumdependent vasodilatation is strongly impaired following elevation of BP in humans (Panza et al. 1990; Taddei et al. 1998; Kodja and Harrison 1999) as well as in the blood vessels of hypertensive animal models (Matsumura et al. 2000; Ajay and Mustafa 2006; Ajay et al. 2007).

Repeated heating of oils at high temperatures over a long period of time predisposes the oil to undergo thermaloxidation, with a configuration change of fatty acid from $\mathrm{cis}$ to trans isomers. A previous study showed a positive relationship between the dietary consumption of trans fat and the development of endothelial dysfunction (Lopez-Garcia et al. 2005). Endothelial dysfunction is associated with

Received June 15, 2009; revision accepted for publication July 30, 2009. doi:10.1620/tjem.219.71

Correspondence: Kamsiah Jaarin, Department of Pharmacology, Faculty of Medicine, Universiti Kebangsaan Malaysia, Jalan Raja Muda Abdul Aziz, 50300, Kuala Lumpur, Malaysia.

e-mail:kamsiah@medic.ukm.my 
hypertension (Verma and Anderson 2002). It has been demonstrated that oxidized fats provoked alterations in endothelial function leading to impairment in vasorelaxation responses (Owu et al. 1997). Similarly, decrease in endothelium-dependent relaxations may augment the contractile responses of blood vessels.

It has been demonstrated earlier that heated palm oil causes a significant rise in blood pressure (Leong et al. 2008), which is in accordance with an earlier study reporting that rats fed with the oxidized oil exhibit significantly greater rise in BP as compared to the control and fresh-oilfed groups (Osim et al. 1996). The main aim of the present study was to explore the possible biochemical and vascular mechanisms involved in the increased blood pressure following chronic administration of repeatedly heated palm cooking oil.

\section{Materials and Methods}

\section{Experimental Design}

Twenty four adult male Sprague-Dawley rats $(n=24)$ aged three months, weighing 200-280 g were obtained from the Animal Source Unit, Universiti Kebangsaan Malaysia and randomly divided into four groups comprising of six animals each. Ethical approval was obtained from the Universiti Kebangsaan Malaysia Animal Ethics Committee (UKMAEC: FP/FAR/2008/KAMSIAH/9-APR/220-APR-2008FEB-2011) for this study. The animals were housed in stainless-steel cages and kept at room temperature of $27^{\circ} \mathrm{C} \pm 2^{\circ} \mathrm{C}$. The animals were allowed to acclimatize for 1 week, prior to treatment with test diets. All rats had free access to food and tap water throughout the experiment. The first group was fed with basal diet alone (control) and the subsequent groups were fed with basal diet fortified with $15 \%$ weight/ weight $(w / w)$ fresh palm oil (FPO), or palm oil heated five times (5HPO), or palm oil heated ten times (10HPO), respectively for 24 consecutive weeks. Blood pressure was measured at baseline and monthly intervals for 6 months. Plasma was taken prior to treatment, at the third month, and at the end of study. The rats were then sacrificed and thoracic aortas were dissected and placed in physiologic tissue bath for measurement of vascular reactivity to various agents.

\section{Source and Preparation of Palm Oil Diets}

Commercially purchased palm oil (Cap Buruh, Lam Soon Edible Oils, Kuala Lumpur, Malaysia) was used fresh or heated for five times or ten times, according to the modified method of Owu et al. (1998). The heating process involved using $2.5 \mathrm{~L}$ of the oil to fry 1 $\mathrm{kg}$ of sweet potatoes in a stainless-steel wok. Temperature of the heated oil reached about $180^{\circ} \mathrm{C}$ for $10 \mathrm{~min}$. To reheat the oil twice, the hot oil was cooled for five hours, and then the entire frying process was repeated with a fresh batch of sweet potatoes without adding any fresh oil to compensate for oil losses. The process was repeated four and nine times to obtain the five and ten times heated oils. Standard rat chow (Gold Coin, Port Klang, Selangor, Malaysia) was used. The rat chow contained crude fat (minimum 2.5\%), crude protein (maximum 20\%), crude fibre (maximum 5\%), total phosphorus $(0.6-1.2 \%)$, calcium $(0.7-1.4 \%)$, nitrogen free extract $(51 \%)$ and all fat soluble vitamins. It was grinded and formulated by mixing $15 \% \mathrm{w} / \mathrm{w}$ of respective oils prepared, and reformed then dried in an oven at $70^{\circ} \mathrm{C}$ overnight.

\section{Measurement of Blood Pressure}

Systolic blood pressure of rats was measured by the tail cuff method using PowerLab data acquisition systems (ADInstruments, Castle Hill, NSW, Australia).

\section{Measurement of Nitric Oxide (NO) Metabolites}

NO production was indirectly measured by plasma nitrite quantification. The time point for measurement was at the end of 24 weeks (6 months). Samples of $50 \mu \mathrm{L}$ were transferred to a 96-well microtiter plate, followed by the addition of $50 \mu \mathrm{L}$ of modified Griess reagent (Sigma-Aldrich, St. Louis, MO, USA). After incubation for $15 \mathrm{~min}$ at room temperature, nitrite concentration was measured at $540 \mathrm{~nm}$ on Emax ELISA microplate reader using SoftMax Pro Software (Molecular Devices, Sunnyvale, CA, USA). A standard curve with increasing concentration of sodium nitrite (Sigma-Aldrich, St. Louis, MO, USA) was performed in parallel and used for nitrite concentration quantification.

\section{Preparation of Aortic Rings and Pharmacological Studies}

The aortic rings were prepared as described by Ajay and Mustafa (2006). The descending thoracic aorta was excised by midline incision, delineated of excess fat and connective tissues. The aorta was cut transversely into ring segments (3-5 mm width) and were mounted in 5-mL organ baths containing Krebs physiological salt solution of the following compositions (mM): $\mathrm{NaCl} 118.0, \mathrm{KCl} 4.7$, $\mathrm{CaCl}_{2} \cdot 2 \mathrm{H}_{2} \mathrm{O} 2.5, \mathrm{KH}_{2} \mathrm{PO}_{4} 1.2, \mathrm{MgSO}_{4} 1.2$, glucose $11.7, \mathrm{NaHCO}_{3}$ 25.0, and EDTA 0.026 . The bathing solution was continuously aerated with gas oxygen - carbon dioxide $(95: 5, \mathrm{v} / \mathrm{v})$ at $37^{\circ} \mathrm{C}$. The tissues isometric tension $(\mathrm{g})$ was recorded by a force-displacement transducer (F-D-Transducer FT03E, Grass Instruments, West Warwick, RI, USA) coupled to a computerized system (MacLab model 8S, ADInstruments, Castle Hill, NSW, Australia). The aortic rings were then progressively stretched to a basal tension of $1 \mathrm{~g}$ and allowed to equilibrate for 30 to $45 \mathrm{~min}$. During this period, the bathing solution was changed every $15 \mathrm{~min}$ and if needed, the resting tension was readjusted to $1 \mathrm{~g}$.

After the equilibration period, the experiments were initiated by obtaining a reference contractile response to isotonic $\mathrm{KCl}$ solution (high $\mathrm{K}^{+}, 80 \mathrm{mM}$ ). Following the washout of responses to high $\mathrm{K}^{+}$, the cumulatively increasing concentration of relaxation responses to acetylcholine (ACh $10^{-10} \mathrm{M}$ to $10^{-5} \mathrm{M}$ ) and sodium nitroprusside (SNP $10^{-11} \mathrm{M}$ to $10^{-6} \mathrm{M}$ ) were recorded in phenylephrine (PE $10^{-6} \mathrm{M}$ ) precontracted aortic rings. In addition, the contractile responses to cumulatively increasing concentration of $\mathrm{PE}\left(10^{-10} \mathrm{M}\right.$ to $\left.10^{-5} \mathrm{M}\right)$ were also recorded in the rings. The rings were constricted with phenylephrine $\left(\mathrm{PE}, 10^{-7} \mathrm{M}\right)$ to test the endothelial integrity with a single addition of acetylcholine (ACh $10^{-5} \mathrm{M}$ ) after washout of responses to high $\mathrm{K}^{+}$. Only the endothelial intact rings, the rings more than $50 \%$ relaxation to ACh, were used (Ajay and Mustafa 2006). Different aortic rings with intact endothelium were used in each experiment.

\section{Drugs}

Acetylcholine chloride, phenylephrine-HCl (Sigma Chemical Co, St. Louis, MO, USA), sodium nitroprusside and Krebs salts (BDH Limited and BDH Laboratory Supplies, Poole, England) were used.

\section{Statistical analyses}

Results were expressed as mean \pm SEM. Values of $p$ less than 0.05 were considered significant. Normality of the data was deter- 
mined using Kolmogorov-Smirnov test. Paired student's $t$ test was used to analyze level differences between before and after six months of treatment data. To analyze blood pressure, nitric oxide metabolites and vascular reactivity parameters among the tested groups, analysis of variance (ANOVA) followed by Tukey's Honestly Significant Differences (HSD) post-hoc test was performed. Correlation between nitric oxide metabolite and blood pressure levels was analyzed using Pearson's correlation test for all the animals irrespective of treatment groups. Data which were not normally distributed were analyzed using non-parametric tests i.e. Kruskal-Wallis and Mann-Whitney $U$ tests. All statistical analyses were conducted using the Statistical Package for Social Sciences (SPSS) version 13.0 software (SPSS Inc, Chicago, IL, USA).

\section{Results}

\section{Changes in Body Weight}

The body weight in all groups consisting of control and experimental groups fed with FPO, 5HPO or 10HPO showed a significant stepwise increase $(p<0.05)$ with time
(Table 1). However, body weight was higher in the $10 \mathrm{HPO}$ group as compared to other groups.

\section{Changes in Blood Pressure}

The rats in control and FPO groups showed no significant changes in blood pressure. There was a significant increase $(p<0.05)$ in blood pressure at the end of study for $5 \mathrm{HPO}$ and $10 \mathrm{HPO}$ groups with increment of $24 \%$ and $30 \%$, respectively (Fig. 1).

\section{Changes in the Plasma Level of Nitric Oxide Metabolites}

There was a $28 \%$ elevation in nitric oxide metabolite levels $(p<0.05)$ for rats fed with FPO. On the other hand, $5 \mathrm{HPO}$ and 10HPO groups reduced the nitrites levels by $25 \%$ and $33 \%$, respectively (Fig. 2)

Table 1. Body weight and food intake in rats fed with palm oil diets.

\begin{tabular}{ccccc}
\hline Groups & Body weight $(\mathrm{g})$ & $p$ value & $\begin{array}{c}\text { Food Intake } \\
(\mathrm{g} / \text { week })\end{array}$ & $p$ value \\
\hline Control & $286.6 \pm 33.0$ & na & $171.4 \pm 6.63$ & na \\
FPO & $287.8 \pm 16.4$ & 1.000 & $141.3 \pm 1.62^{\mathrm{a}}$ & 0.004 \\
5 HPO & $290.0 \pm 27.6$ & 0.999 & $148.4 \pm 4.93$ & 0.082 \\
$10 \mathrm{HPO}$ & $310.7 \pm 17.9$ & 0.821 & $145.8 \pm 3.49^{\mathrm{a}}$ & 0.009 \\
\hline
\end{tabular}

a, significant difference $(p<0.05)$ versus control.

na, non-applicable; FPO, fresh palm oil; 5HPO, palm oil heated five times; 10HPO, palm oil heated ten times.

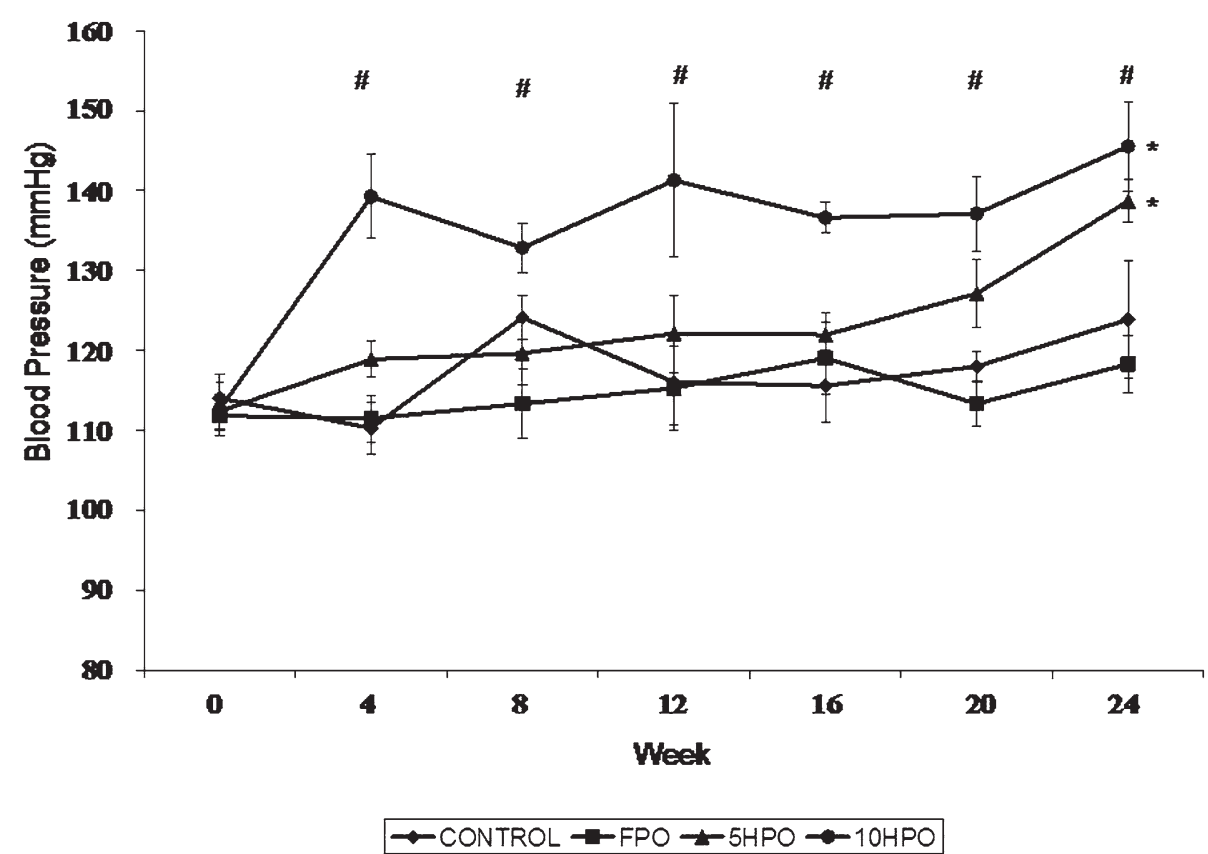

Fig. 1. Changes in blood pressure. Shown are the changes in blood pressure following consumption of basal diet (control), diet fortified with fresh (FPO), palm oil heated five times (5HPO) or palm oil heated ten times (10HPO). Mean \pm SEM. *significant difference $(p<0.05)$ between pre- and post-treatment values for same group. \# significant difference $(p<0.05)$ between groups. 


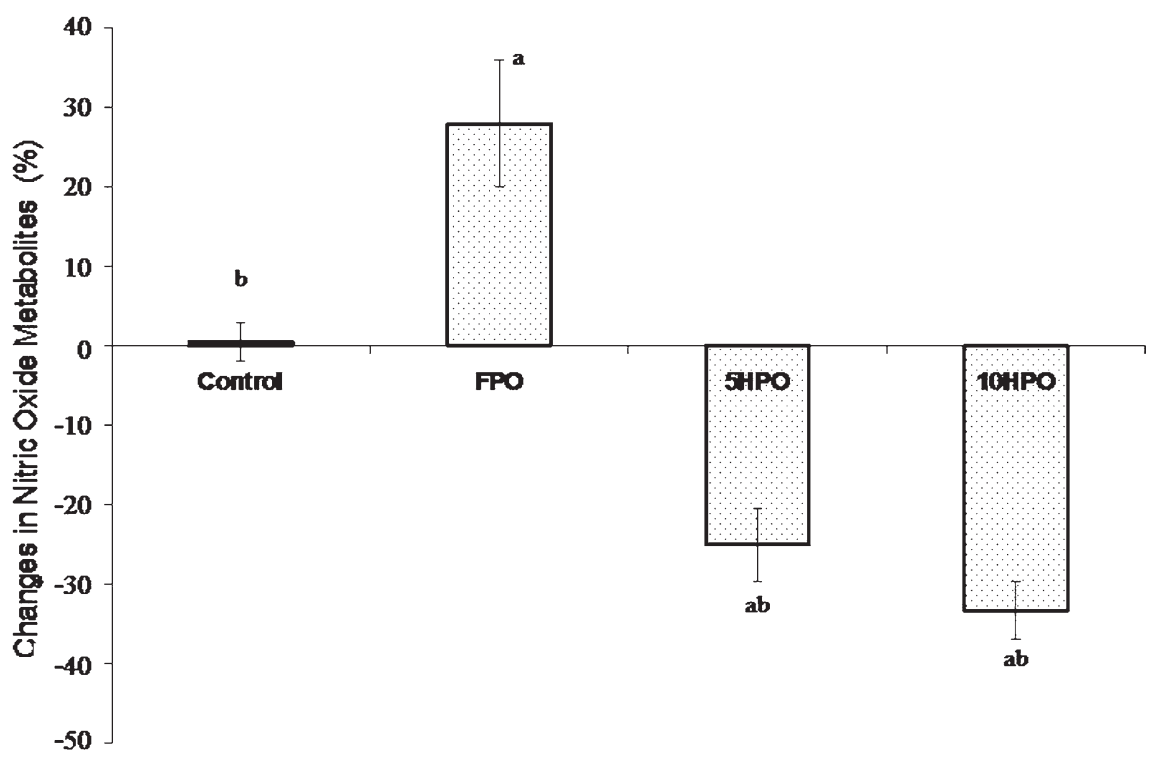

Fig. 2. Changes in plasma nitric oxide metabolites. Shown are the \%changes in nitric oxide metabolite levels in rats fed with basal diet (control), diet fortified with fresh (FPO), palm oil heated five times (5HPO) or palm oil heated ten times (10HPO). Mean \pm SEM.

a, significant difference $(p<0.05)$ versus control.

$\mathrm{b}$, significant difference $(p<0.05)$ versus FPO group.

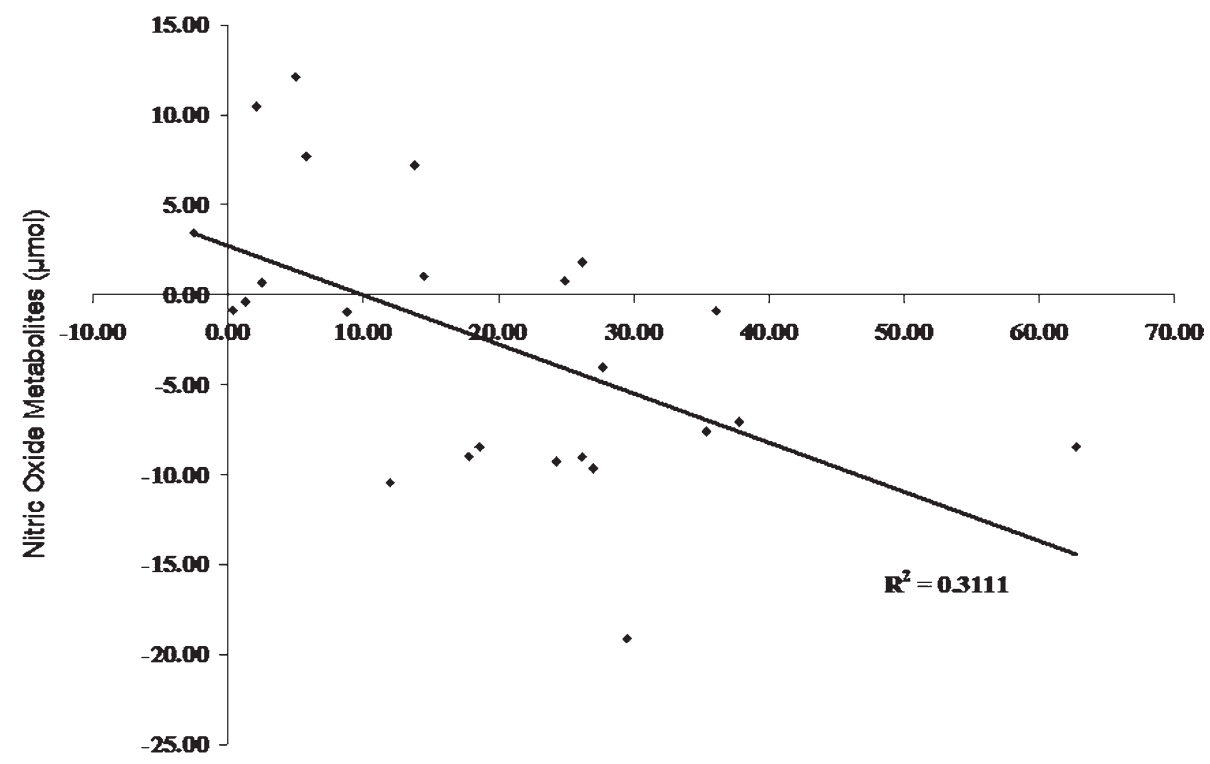

Blood Pressure ( $\mathrm{mm} \mathrm{Hg}$ )

Fig. 3. The correlation between blood pressure and nitric oxide metabolite levels in rats. $r=-0.558, p=0.005$.

\section{Correlation between Blood Pressure and Nitric Oxide Metabolites}

There was an inverse relationship between blood pressure and plasma nitric oxide metabolites (Fig. 3). This suggests that the elevation in blood pressure may be a consequence of a reduction in the production of nitric oxide in the vascular wall.

\section{Relaxation to ACh and SNP}

ACh (Fig. 4A) and SNP (Fig. 4B) concentrationdependently relaxed the PE pre-contracted aortic rings from various groups of rats. Relaxant effect of $\mathrm{ACh}$ at maximal concentration $\left(10^{-5} \mathrm{M}\right)$ tested was significantly reduced $(p<$ $0.05)$ in aortic rings obtained from $5 \mathrm{HPO}(84 \% \pm 2.38)$ and $10 \mathrm{HPO}(76 \% \pm 3.11)$ groups as compared to the control $(94 \% \pm 3.36)$ and the FPO $(99 \% \pm 3.65)$ groups. In addition, vasodilatation in response to SNP at its highest con- 


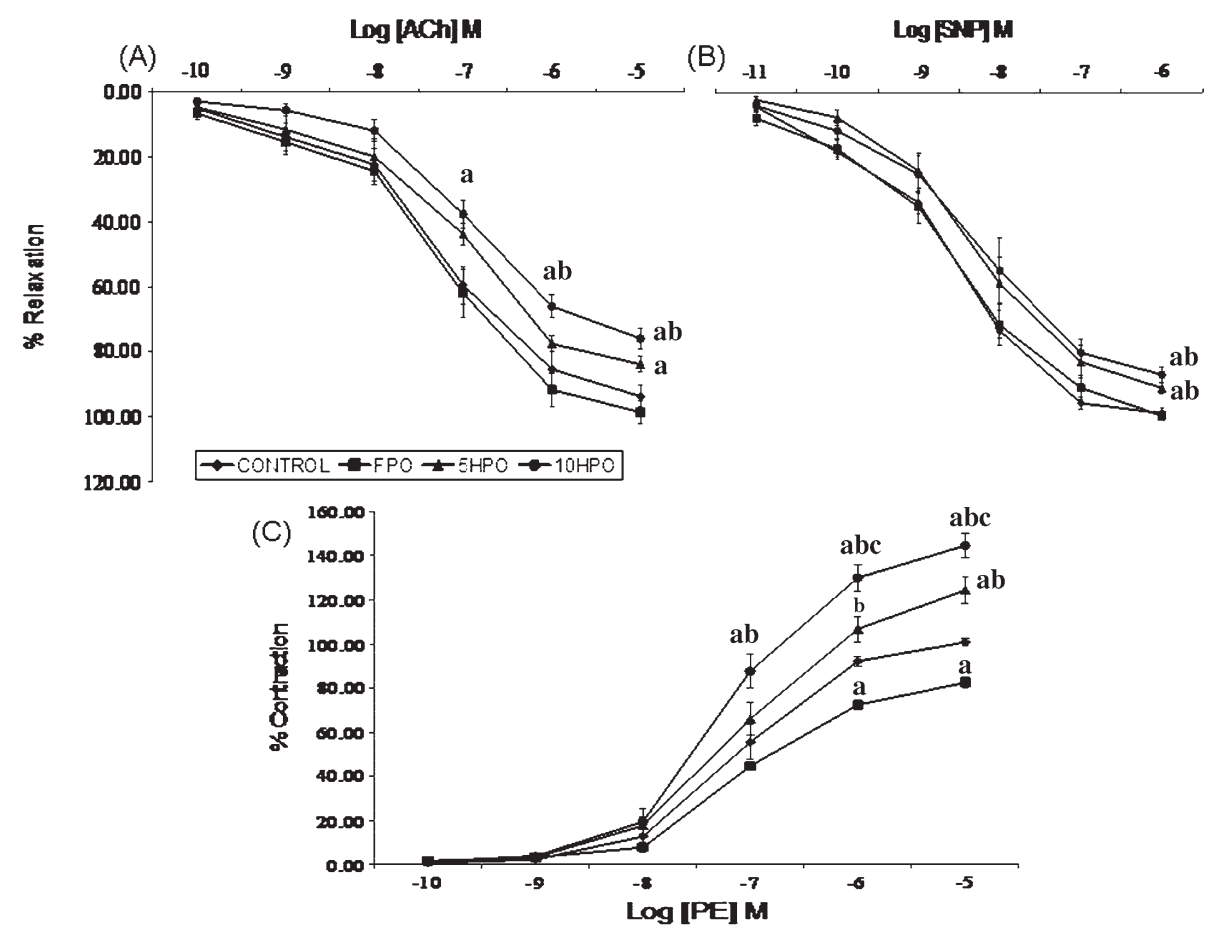

Fig. 4. Effects of vasoactive substances on responsibility of the isolated aortic rings.

Aortic rings were isolated from control, fresh (FPO), palm oil heated five times (5HPO) or palm oil heated ten times $(10 \mathrm{HPO})$ groups, and their responses to each drug were measured. Shown are the endothelium-dependent relaxations induced by acetylcholine (ACh) (A), endothelium-independent relaxations induced by sodium nitroprusside (SNP) (B), and $\alpha_{1}$-adrenergic-receptor-mediated contractions induced by phenylephrine (PE) (C). Data are shown as Mean \pm SEM. a, significant difference $(p<0.05)$ versus control.

$\mathrm{b}$, significant difference $(p<0.05)$ versus FPO group.

$c$, significant difference $(p<0.05)$ versus 5HPO group.

centration $\left(10^{-6} \mathrm{M}\right)$ was significantly attenuated $(p<0.05)$ in aortic rings taken from 5HPO $(99 \% \pm 1.75)$ and $10 \mathrm{HPO}$ $(94 \% \pm 2.58)$ groups. For ACh and SNP, their relaxation effects remained similar in aortic rings of FPO rats $(108 \% \pm$ $1.55)$, as compared to the aortic rings taken from control rats $(107 \% \pm 1.60)$.

\section{Contractile response to $P E$}

Cumulative additions of PE elicited a concentrationdependent contraction in all aortic ring types studied (Fig. 4C). The vasoconstriction in response to PE at the highest concentration $\left(10^{-5} \mathrm{M}\right)$ tested was significantly augmented $(p<0.05)$ in aortic rings of 5HPO $(124 \% \pm 5.79)$ and $10 \mathrm{HPO}(145 \% \pm 5.42)$, as compared to control $(101 \% \pm$ $1.82)$ and $\mathrm{FPO}(82 \% \pm 2.63)$.

\section{Discussion}

Prolonged feeding of the male Sprague-Dawley rats with FPO, 5HPO or 10HPO did not cause the decrease in body weight. However, the 10HPO group showed a higher body weight gain among the treatment groups even though with a lower intake of food. The food intake was more for the normal control group as compared to the 5HPO and $10 \mathrm{HPO}$ groups. Although the food intake was less for the $5 \mathrm{HPO}$ and the $10 \mathrm{HPO}$ groups, there was a gain in weight in these two groups as compared to the control group. Repeated heating of the cooking oil results in the formation of trans fatty acid that behaves like saturated fatty acid in terms of the effects on cholesterol (Mensink and Katan 1990; Sundram et al. 1997). Increase in the low-density lipoprotein cholesterol and the triglyceride levels and reduction of the high-density lipoprotein cholesterol may explain the weight gain as observed in the experimental groups fed with repeatedly heated palm oil.

There was a significant increase in blood pressure for the groups fed with repeatedly heated palm oil. This finding was in accordance with our previous study (Leong et al. 2008). In fact, Soriguer et al. (2003) reported that repeatedly using the same frying oil was linked to an increased risk of hypertension. Elevation of BP following chronic ingestion of 5HPO and 10HPO might be linked to changes in endothelial function i.e. reduction in nitric oxide (NO) bioavailability. FPO did not show significant changes in blood pressure but showed a tendency to lowering it. This finding was contradictory to the other studies that had reported a significant reduction in the BP. This may be due to the different types of the animals and palm oil used in the experiments. For the present study, FPO was fed to normal rats instead of spontaneously hypertensive rats (Aguila et al. 2005; Medeiros et al. 2005), or Dahl-Salt sensitive rats 
Table 2. The constituents of dietary palm oil.

\begin{tabular}{lrr}
\hline \multicolumn{1}{c}{ Constituents } & Per Serving $(14 \mathrm{~g})$ & Per $100 \mathrm{~g}$ \\
\hline Energy & $126 \mathrm{kcal}$ & $900 \mathrm{kcal}$ \\
Protein & $0 \mathrm{~g}$ & $0 \mathrm{~g}$ \\
Carbohydrate & $0 \mathrm{~g}$ & $0 \mathrm{~g}$ \\
Total fats & $14 \mathrm{~g}$ & $100 \mathrm{~g}$ \\
MUFA & $6.3 \mathrm{~g}$ & $45 \mathrm{~g}$ \\
PUFA & $1.7 \mathrm{~g}$ & $12 \mathrm{~g}$ \\
SFA & $6.0 \mathrm{~g}$ & $43 \mathrm{~g}$ \\
Trans fatty acid & $0 \mathrm{~g}$ & $0 \mathrm{~g}$ \\
Cholesterol & $0 \mathrm{mg}$ & $0 \mathrm{mg}$ \\
Sodium & $0 \mathrm{mg}$ & $0 \mathrm{mg}$ \\
Vitamin E & $8.4 \mathrm{mg}$ & $60 \mathrm{mg}$ \\
\hline
\end{tabular}

MUFA, monounsaturated fatty acid; PUFA, polyunsaturated fatty acid; SFA, saturated fatty acid.

(Bayorh et al. 2005). Secondly, the animals in previous studies were fed with Carotino oil, a natural vitamin-rich palm oil produced by Palm Oil Research Institute of Malaysia (PORIM) via a patented refining short-path distillation technology (Ganafa et al. 2002; Bayorh et al. 2005). Palm oil is widely used in various parts of the world as cooking oil in both household and food outlets due to its lower cost. The constituents of the palm oil are depicted in Table 2.

FPO is known to contain saturated and unsaturated fatty acid in the ratio of $1: 1$ (Cottrell 1991). Usually, no trans fatty acid is found in the FPO; however, repeatedly heated palm oil results in oxidation of dietary fatty acids, which comprise of low essential fatty acid, low unsaturated fatty acid and high saturated fatty acid (Isong et al. 1996). In addition, repeatedly heated palm oil has reduced vitamin $\mathrm{E}$ constituents such as $\alpha$-tocopherol, $\alpha$-tocotrienol, $\gamma$-tocotrienol and $\delta$-tocotrienol (Adam et al. 2007). Consumption of repeatedly heated soy oil in post-menopausal state may contribute to the development of atherosclerosis because of increased lipid peroxidation (Adam et al. 2008).

$5 \mathrm{HPO}$ and $10 \mathrm{HPO}$ profoundly reduced plasma nitric oxide metabolites as indicated indirectly by measurement of the nitrite and nitrate metabolites. Repeated heating of palm oil may cause destruction of carotenes and vitamin E, all of which are contained in fresh palm oil (Adam et al. 2007). Consumption of repeatedly heated palm oil may not protect against superoxide anions, which may react with NO to form peroxynitrite, a potent cytotoxic oxidant (Halliwell 1997). Thus loss of NO-dependent relaxation and increased peroxynitrite generations contribute to the enhanced vasoconstriction and elevation of blood pressure (Gao and Lee 2001).

In agreement with Ganafa et al. (2002), consumption of FPO increased plasma levels of the nitric oxide metabolites. Esterhuyse et al. (2006) reported that dietary red palm oil increased the bioavailability of NO. It has been suggested that natural antioxidants found in the oil may provide some protective effects by decreasing oxidative stress or directly stimulating synthesis of nitric oxide, thereby preserving the bioavailability of NO (Carr and Frei 2000).

NO has been widely demonstrated to be a potent vasodilator and its release may be triggered by several pharmacologically vasoactive substances, such as acetylcholine (Moncada et al. 1991; Moncada and Higgs 1993). Therefore, NO plays a vital regulatory role in determining the balance between the contraction and dilation of vascular smooth muscle (Pérez-Guerrero et al. 2000). The major observation of the current work was that repeatedly heated palm oil attenuated the ACh induced-endothelium-dependent relaxations and the SNP-induced-endothelium-independent relaxations of aortic rings, and enhanced contractions in response to the $\alpha_{1}$-adrenergic agonist PE as compared to rings obtained from control and FPO groups.

In the rat aorta, $\mathrm{ACh}$ induced relaxation by increasing the bioavailability of NO via the release of NO from the endothelial cells. The SNP-induced relaxation is independent of the endothelium and is due to the breakdown of the SNP molecule to yield exogenous NO. NO, which is released, activates guanylate cyclase to increase formation of cyclic GMP, which ultimately causes vascular smooth muscle relaxation. In the present study, repeatedly heated palm oil attenuated the endothelium-dependent relaxation caused by ACh, but had no effect on the relaxant response to SNP. The present data suggest that treatment with the repeatedly heated palm oil was unlikely to exert non-specific attenuation of vascular reactivity, e.g. inhibition of nitric oxide-cGMP relaxant pathway or reduced cGMP production. In contrast, treatment with the repeatedly heated palm oil may reduce the bioavailability of the endotheliumderived NO. Repeatedly heated palm oil has reduced radical scavenging actions and this may result in increased inactivation of NO by the free radicals. A similar alteration in vascular responses has been reported in rat aorta after chronic consumption of thermally oxidized palm oil (Owu et al. 1997).

The increase in blood pressure observed following administration of the repeatedly heated palm oil is likely due to the reduction in NO release from the vascular endothelium and the concomitant increase in vasoconstriction and total peripheral resistance. It may be postulated that free radicals may be involved in the pathogenesis of heated oil-induced hypertension. When palm oil is heated repeatedly during cooking, not only it generates free radicals but also reduces the content of antioxidants and vitamins, leading to oxidative stress. Increased free radical generation contributes to endothelial dysfunction, which decreases the bioavailability of endothelium-dependent relaxants, such as NO.

\section{Conclusion}

In summary, fresh palm oil has no detrimental effects on blood pressure with a significant elevation in nitric oxide metabolite levels and reduction in contractile responses to 
phenylephrine. In contrast, chronic consumption of repeatedly heated palm oil causes an increase in blood pressure. The blood pressure rising effect of the heated oil might be mediated via an increased in vascular reactivity. The increase in vascular contraction is likely to be due to a significant reduction in plasma nitric oxide metabolite levels.

\section{Acknowledgments}

The study was funded by grant UKM-GUP-SK-08-21-299. The authors would like to thank Ms. Azizah Osman and staff members in the Pharmacology Department of University of Malaya for technical assistance.

\section{References}

Adam, S.K., Sulaiman, N.A., Mat Top, A.G. \& Jaarin, K. (2007) Heating reduces vitamin $\mathrm{E}$ content in palm and soy oils. Malays. J. Biochem. Molec. Biol., 15, 76-79.

Adam, S.K., Das, S., Soelaiman, I.N., Umar, N.A. \& Jaarin, K. (2008) Consumption of repeatedly heated soy oil increases the serum parameters related to atherosclerosis in ovariectomized rats. Tohoku J. Exp. Med., 215, 219-226.

Aguila, M.B., Pinheiro, A.R. \& Mandarim-de-Lacerda, C.A. (2005) Spontaneously hypertensive rats left ventricular cardiomyocyte loss attenuation through different edible oils long term intake. Int. J. Cardiol., 100, 461-466.

Ajay, M. \& Mustafa, M.R. (2006) Effects of ascorbic acid on impaired vascular reactivity in aortas isolated from agematched hypertensive and diabetic rats. Vascul. Pharmacol., 45, 127-133.

Ajay, M., Achike, F.I. \& Mustafa, M.R. (2007) Modulation of vascular reactivity in normal, hypertensive and diabetic rat aortae by a non-antioxidant flavonoid. Pharmacol. Res., 55, 385-391.

Bayorh, M.A., Abukhalaf, I.K. \& Ganafa, A.A. (2005) Effect of palm oil on blood pressure, endothelial function and oxidative stress. Asia Pac. J. Clin. Nutr., 14, 325-339.

Carr, A. \& Frei, B. (2000) The role of natural antioxidants in preserving the biological activity of endothelium-derived nitric oxide. Free Rad. Biol. Med., 28, 1806-1814.

Cottrell, R.C. (1991) Introduction: nutritional aspects of palm oil. Am. J. Clin. Nutr., 53, 989s-1009s.

Esterhuyse, J.S., van Rooyen, J., Strijdom, H., Bester, D. \& du Toit, E.F. (2006) Proposed mechanisms for red palm oil induced cardioprotection in a model of hyperlipidaemia in the rat. Prostaglandins Leukot. Essent. Fatty Acids, 75, 375-384.

Ferrara, L.A., Raimondi, A.S., d'Episcopo, L., Guida, L., Dello Russo, A. \& Marotta, T. (2000) Olive oil and reduced need for antihypertensive medications. Arch. Intern. Med., 160, 837842.

Furchgott, R.F. \& Vanhoutte, P.M. (1989) Endothelium-derived relaxing and contracting factors. FASEB J., 3, 2007-2018.

Ganafa, A.A., Socci, R.R., Eatman, D., Silvestrov, N., Abukhalaf, I.K. \& Bayorh, M.A. (2002) Effect of palm oil on oxidative stress-induced hypertension in Sprague-Dawley rats. Am. J. Hypertens., 15, 725-731.

Gao, Y.J. \& Lee, R.M.K.W. (2001) Hydrogen peroxide induces a greater contraction in mesenteric arteries of spontaneously hypertensive rats through thromboxane $\mathrm{A}_{2}$ production. $B r . J$. Pharmacol., 134, 1639-1646.

Halliwell, B. (1997) What nitrates tyrosine? Is nitrotyrosine specific as a biomarker of peroxynitrite formation in vivo? FEBS Lett., 411, 157-160.

Isong, E.U., Essien, E.U., Umoh, I.B., Ifon, E.T. \& Eka, O.U. (1996) Effects of ingested thermoxidised palm oil on lipid distribution in rat. Nutr. Res., 16, 773-780.

Kodja, G. \& Harrison, D. (1999) Interaction between NO and reactive oxygen species: pathophysiological importance in atherosclerosis, hypertension, diabetes and heart failure. Cardiovasc. Res., 43, 562-571.

Leong, X.F., Aishah, A., Nor Aini, U., Das, S. \& Jaarin, K. (2008) Heated palm oil causes rise in blood pressure and cardiac changes in heart muscle in experimental rats. Arch. Med. Res., 39, 567-572.

Lopez-Garcia, E., Schulze, M.B., Meigs, J.B., Manson, J.E., Rifai, N., Stampfer, M.J., Willett, W.C. \& Hu, F.B. (2005) Consumption of trans fatty acids is related to plasma biomarkers of inflammation and endothelial dysfunction. J. Nutr., 135, 562-566.

Matsumura, Y., Kita, S., Ohgushi, R. \& Okui, T. (2000) Effects of sesamin on altered vascular reactivity in aortic rings of deoxycorticosterone acetate-salt-induced hypertensive rat. Biol. Pharm. Bull., 23, 1041-1045.

Medeiros, F.J., Mothe, C.G., Aguila, M.B. \& Mandarim-deLacerda, C.A. (2005) Long-term intake of edible oils benefits blood pressure and myocardial structure in spontaneously hypertensive rat (SHR) and streptozotocin diabetic SHR. Prostaglandins Other Lipid Mediat., 78, 231-248.

Mensink, R.P. \& Katan, M.B. (1990) Effect of dietary trans fatty acids on high-density and low-density lipoprotein cholesterol levels in healthy subjects. N. Engl. J. Med., 323, 439-445.

Moncada, S., Palmer, R.M. \& Higgs, E.A. (1991) Nitric oxide: physiology, pathophysiology, and pharmacology. Pharmacol. Rev., 43, 109-142.

Moncada, S. \& Higgs, E.A. (1993) The L-arginine-nitric oxide pathway. N. Engl. J. Med., 329, 2002-2012.

Osim, E.E., Owu, D.U. \& Etta, K.M. (1996) Arterial pressure and lipid profile in rats following chronic ingestion of palm oil diets. Afr. J. Med. Med. Sci., 25, 335-340.

Owu, D.U., Osim, E.E. \& Orie, N.N. (1997) Altered responses of isolated aortic smooth muscle following chronic ingestion of palm oil diets in rats. Afr. J. Med. Med. Sci., 26, 83-86.

Owu, D.U., Osim, E.E. \& Ebong, P.E. (1998) Serum liver enzymes profile of Wistar rats following chronic consumption of fresh or oxidized palm oil diets. Acta Trop., 69, 65-73.

Panza, J.A., Quyyumi, A.A., Brush, J.E. Jr. \& Epstein, S.E. (1990) Abnormal endothelium-dependent vascular relaxation in patients with essential hypertension. N. Engl. J. Med., 323, 22-27.

Pérez-Guerrero, C., Álvarez de Sotomayor, M., Herrera, M.D. \& Marhuenda, E. (2000) Endothelium modulates contractile response to simvastatin in rat aorta. Z. Naturforsch. C., $\mathbf{5 5}$, 121-124.

Psaltopoulou, T., Naska, A., Orfanos, P., Trichopoulos, D., Mountokalakis, T. \& Trichopoulou, A. (2004) Olive oil, the Mediterranean diet, and arterial blood pressure: the Greek European Prospective Investigation into Cancer and Nutrition (EPIC) study. Am. J. Clin. Nutr., 80, 1012-1018.

Roberts, C.K., Vaziri, N.D., Wang, X.Q. \& Barnard, R.J. (2000) Enhanced NO inactivation and hypertension induced by a high-fat, refined-carbohydrate diet. Hypertension, 36, 423429.

Roberts, C.K., Barnard, R.J., Sindhu, R.K., Jurczak, M., Ehdaie, A. \& Vaziri, N.D. (2005) A high-fat, refined-carbohydrate diet induces endothelial dysfunction and oxidant/antioxidant imbalance and depresses NOS protein expression. J. Appl. Physiol., 98, 203-210.

Rubanyi, G.M. (1988) Vascular effects of oxygen-derived free radicals. Free Radic. Biol. Med., 4, 107-120.

Soriguer, F., Rojo-Martínez, G., Dobarganes, M.C., GarcíaAlmeida, J.M., Esteva, I., Beltrán, M., Ruiz De Adana, M.S., Tinahones, F., Gómez-Zumaquero, J.M., García-Fuentes, E. \& González-Romero, S. (2003) Hypertension is related to the degradation of dietary frying oils. Am. J. Clin. Nutr., 78, 1092-1097.

Sundram, K., Ismail, A., Hayes, K.C., Jeyamalar, R. \& Pathmanathan, R. (1997) Trans (elaidic) fatty acids adversely 
affect the lipoprotein profile relative to specific saturated fatty acids in humans. J. Nutr., 127, 514s-520s.

Taddei, S., Virdis, A., Ghiadoni, L., Magagna, A. \& Salvetti, A. (1998) Vitamin C improves endothelium-dependent vasodilation by restoring nitric oxide activity in essential hypertension. Circulation, 97, 2222-2229.

Verma, S. \& Anderson, T.J. (2002) Fundamentals of endothelial function for the clinical cardiologist. Circulation, 105, 546549. 